\title{
DIAGNOSTICS AND TREATMENT OF CERVICAL CAUSES OF INFERTILITY
}

\author{
Aleksandar K. Kunev \\ Medical Center Dr Kunev, \\ Ruse, \\ Bulgaria
}

\author{
Corresponding Author: \\ Aleksandar K. Kunev \\ Medical Center Dr. Kunev \\ 87, Borisova Str. \\ Ruse, 7000 \\ Bulgaria \\ e-mail:alexdrag1973@abv.bg
}

Received: April 30, 2019

Revision received: June 19, 2019

Accepted: July 30, 2019

\section{Summary}

Nowadays, infertility is a problem that affects an increasing number of people. The causes of infertility in a couple may be due to a variety of factors female, male or unexplained. One of the common problems associated with infertility in women is related to uterine cervical diseases. The cervix is an essential part of the sperm passage, so various disorders in the cervix structure and function may be the cause of infertility. The study aimed to identify the leading cervical causes of female infertility, methods of treatment and their success. The most common problems of cervical origin are cervical polyps and stenosis of the cervical canal. They are easily diagnosed with a routine gynaecological examination and ultrasound examination. Polyps are removed through polypectomy, and after that, a natural pregnancy can be achieved. In the case of stenosis of the cervical canal, there are two treatment options - dilation or intrauterine insemination (IUI). In younger patients and lack of male factor in the couple, dilation is performed. Dilation is mechanical with classic Hegar dilatiors or with synthetic hygroscopic dilatiors (Dilapan). If, in addition to the stenosis of the cervical canal in a woman, there is a male factor, treatment with IUI is preferred. Methods for cervical factor treatment vary in their success rate but are generally characterised by good results.

Key words: infertility, female, uterine cervical diseases, insemination

\section{Introduction}

When classifying the origin of infertility, the normal distribution is $35 \%$ female, $35 \%$ male and $30 \%$ having problems in both partners or a sterility problem of unknown origin. The cervical factor is a significant part of all the reasons affecting the movement of sperm from the vagina to the egg cell because the cervix is a part of the sperm way to the egg.

The natural insemination in humans is the deposition of the ejaculate in the vagina during the coitus. The ejaculate consists of sperms and plasma and is slightly alkaline $(\mathrm{pH} 7.2 \div 8.0)$, but the vagina is acidic $(\mathrm{pH} 4.0 \div 5.0)$. Sperm here begins the process of capacitation - going to their 
mature hyperactive form, which able to fertilise an egg. First, for a short time under the acidic $\mathrm{pH}$ of the vagina, movement stops, and a large number of spermatozoa die, then the vaginal content is neutralised, and the flow is restored. The surviving spermatozoa are directed from the vagina to the cervix, through the cervical canal, from there through the cavity of the uterus to the uterine tubules and reach their ampoule, where fertilisation takes place [1].

The speed of human spermatozoa is 4 millimeter per minute or $\mathrm{mm} / \mathrm{min}$, but most of them are considerably slower $(1 \mathrm{~mm} / \mathrm{min})$, and their size is 55 microns. Energy for the movement of sperm is provided by fructose in the ejaculate, and the common path that has to be passed is about $25-30 \mathrm{~cm}$. So, "the purpose of their journey"is reached for $45 \mathrm{~min}$. The upward movement of sperm in the female reproductive tract is also aided by female orgasm, contractions of the uterine tubules and uterine muscles. Sperm fertilising ability in vivo is up to 72 hours [2].

The study aimed to identify the main cervical factors affecting sperm movement in the female reproductive tract, as well as to suggest methods for their treatment.

\section{Materials and Methods}

\section{Patients}

A retrospective analysis of 252 patients with reproductive problems who had been treated at the Medical Center for Reproductive Health Dr Shterev in the period 2012-2015 and in Medical centre Dr Kunev in the period 2017-2019 was carried out. Of these patients, 92 were diagnosed with cervical factor as a cause of infertility. They were divided into different groups, depending on the type of cervical pathology and the method of treatment chosen by the doctor. All patients included in the study had been diagnosed with a cervical disorder. They were divided into several groups: the first group included patients with polyps treated with polypectomy; the second group - patients with cervical canal stenosis, divided into three subgroups depending on the type of treatment (classic dilation with Hawar dilators, dilation with a synthetic hygroscopic dilator, intrauterine insemination).

\section{Methods}

We used the following methods:

\section{Information methods}

Taking a past and family case history of the couples);

\section{Clinical methods}

Taking the obstetric history of the woman (analysis of her objective condition and gynaecological status by conducting a standard gynaecological and ultrasound examination) and andrological examination of the man and confirmation of pregnancy;

\section{Surgical methods under anaesthesia}

Methods for removing polyps of the cervix or mechanical dilation of the cervical canal in cases of stenosis;

\section{Non-invasive methods}

For cervix dilation by using a hygroscopic cervical dilator;

Intrauterine insemination (IUI) as part of assisted reproductive techniques (ART) including sperm preparation and the introduction of treated spermatozoa into the uterine cavity by a special IUI catheter;

\section{Statistical methods}

The data was entered and processed with IBM SPSS Statistics 23.0, and presented in tabular form is the frequency distribution of the relevant features, divided into groups of study (Descriptive analysis) and by using visual analysis to illustrate the results obtained.

\section{Cervical factors of infertility - diagnostics} and methods of treatment

The cervix is the lower part of the uterus in the human female reproductive system. It is usually 25 to $45 \mathrm{~mm}$ long. The narrow, central cervical canal runs along its entire length, connecting the uterine cavity and the lumen of the vagina. The cervical canal has two openings - orificium externum canalis cervicalis (OECC) and orificium internum canalis cervicalis (OICC). It is lined with a single-layer, cylindrical, mucusproducing epithelium, which at its upper end passes into the endometrium, and downturns into a multilayer flat epithelium. It produces a mild alkaline reaction, rich in fructose and mucopolysaccharides. Also, there is a secreted Immunoglobulin class A of the so-called MALTsystem. On the sides of the cervical canal are formed cervical crypts which are transverse extensions of the endocervical glands. When the cervical canal is wide enough, they also serve as a reservoir for the sperm (Figure 1). 


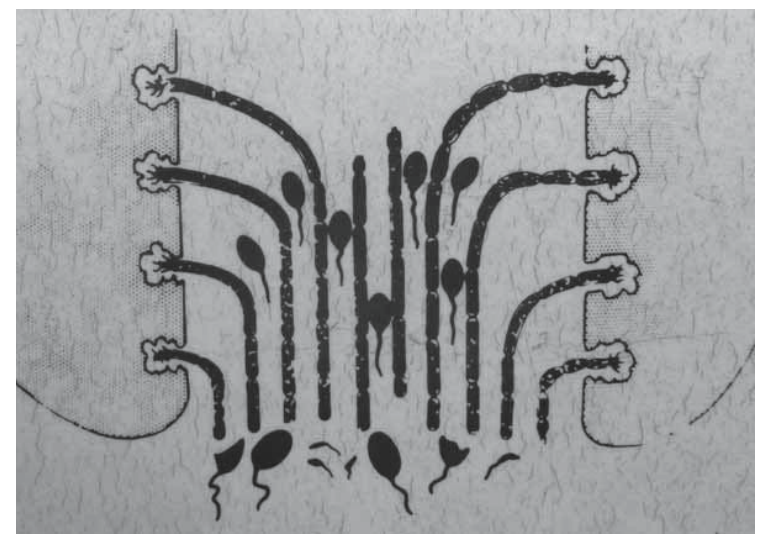

Figure 1. Cervical canal with formed cervical crypts

Different parts of the cervical canal produce a different type of mucus. The lower parts produce thick mucus that serves as a stopper and protects against bacteria and sperm. It is called G-type (Figure 2).

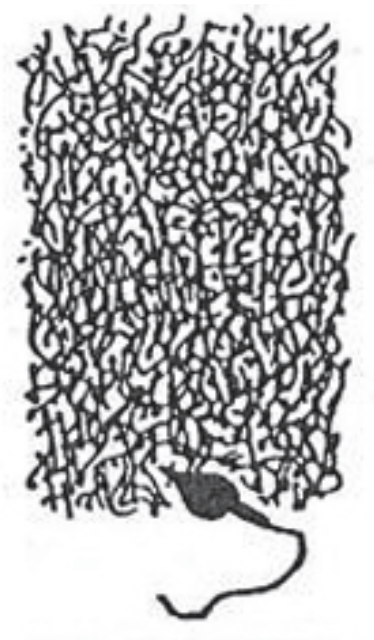

G TYPE MUCUS

Figure 2. G-type mucus

In the upper part of the cervical canal, L-mucus is formed, which captures defective spermatozoa and supports the activity of the next type of mucus. The S-type mucus is formed in the upper cervical compartments and is responsible for sperm transport at the time of ovulation (Figure 3 ).

The L-mucus is like a labyrinth in which there are pointless S-type canals, but the time of ovulation; these S-type mucus canals are piled up into the OICC (the inner open cervical canal).

The combination of alkaline secretions of mucus, which is $\mathrm{pH}$-identical to that of the ejaculate, and the high level of fructose and enzymes provide a beneficial environment for survival of sperm in the cervix. Usually, between the 10th and 12th day of ovulation, the cervical mucus is abundant and fills the cervical canal [3].

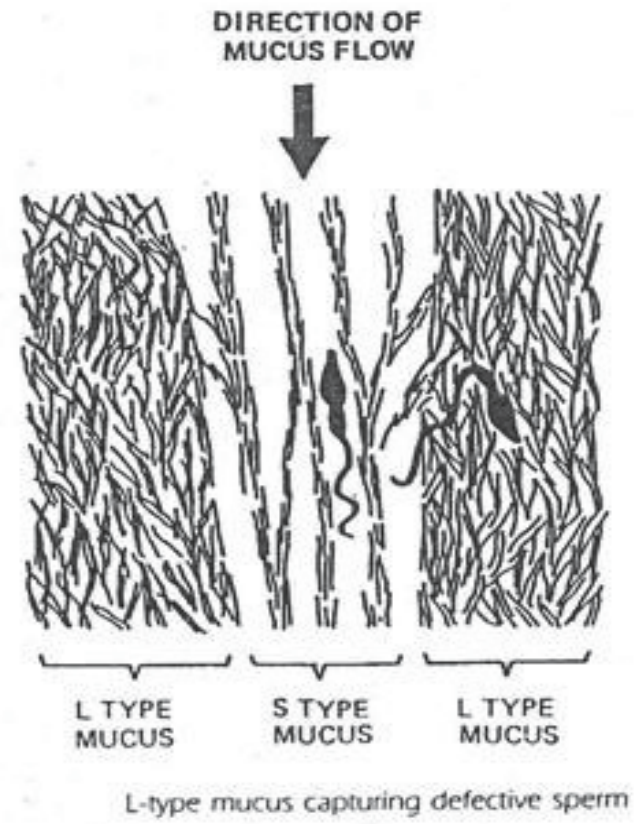

Figure 3. L-type and S-type mucus

The shape of OECC is of 3 types:

Oval

This form of OECC is typical for women who have given natural birth. It corresponds with good fertility because of the low probability of stenosis of the cervical canal and perfect semen transport through the mucus (Figure 4).

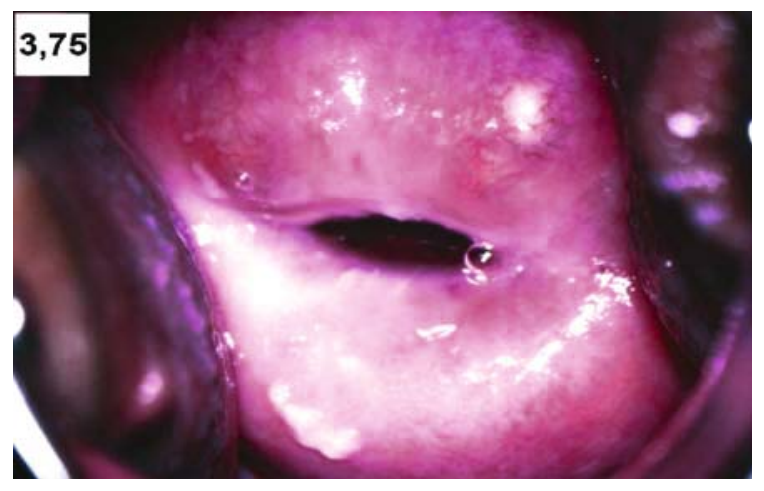

Figure 4. Cervical canal with oval shaped OECC

\section{Round}

This form of OECC occurs in women who have not given birth. It also has an abundant amount of mucus in the canal during ovulation and suggests good fertility (Figure 5). 


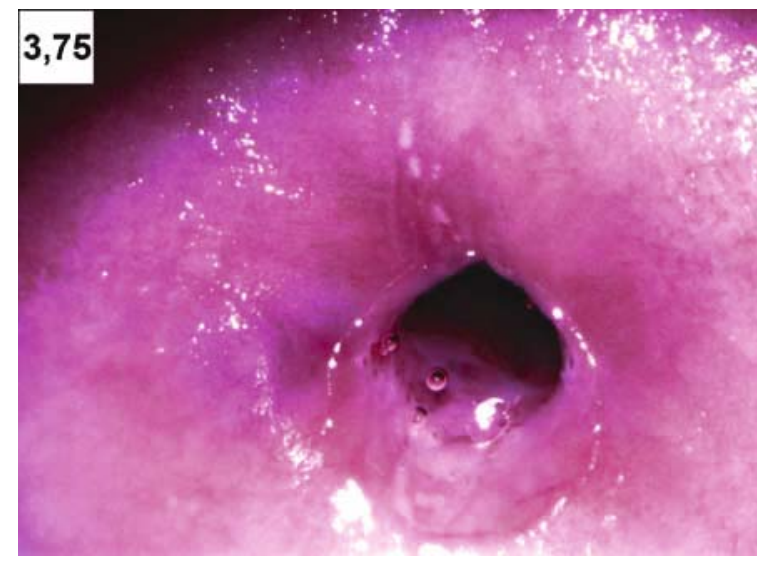

Figure 5. Cervical canal with round shaped OECC

\section{Spot-shaped}

This shape is most commonly seen in women who have no children (especially before 16 years) and is generally associated with congenital stenosis of the cervical canal. Of all types of OECC, only this one suggests stenosis, and it is always primary and congenital, but not all women with spot-shaped OECC have infertility problems (Figure 6) [4].

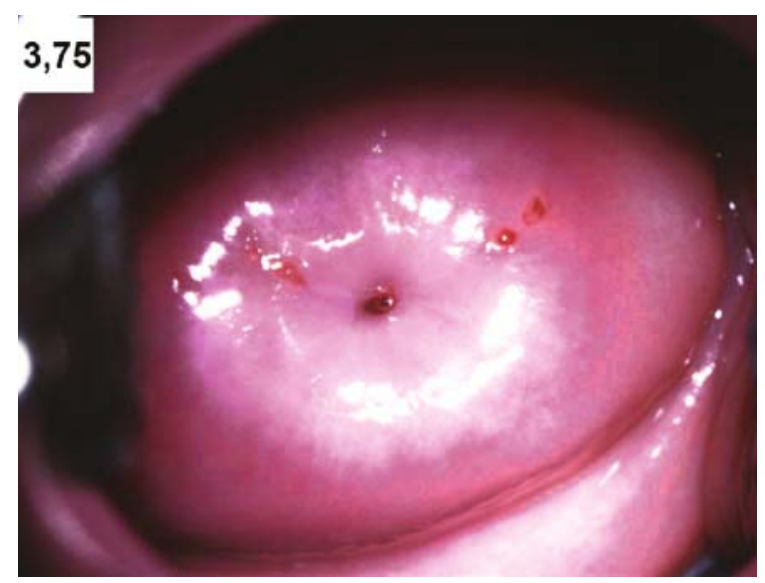

Figure 6. Cervical canal with spot-shaped OECC

Low cervix score (LCS) is determined by the visual assessment of 3 ovulatory parameters:

Quantity of cervical mucus - from 0 to 3 points, from total lack to abundance;

Width of the hole - from 0 to 3 points depending on whether it is closed or wide open;

The pungency of the secretion - from 0 to 3 points $(0$ points if it is missing at all, 1 point if it falls to $1 / 3$ of the vagina, 2 points if it falls to $1 / 2$ of the length of the vagina or 3 points if it falls to the vulva) [5].

\section{Ultrasound}

Ultrasound gives the best picture of whether there is a stenosis of the cervical canal or not. Serial sketches are performed on days 5, 7 and 10 of the menstrual cycle to assess the accumulation of secretion in the canal, and whether the amount corresponds to the type of endometrial mucosa. Ideally, on the 10-12 day mucosa "M" type, 8-12 $\mathrm{mm}$ should have about 2-3 $\mathrm{mm}$ of secretion in diameter in the canal. The signs of ovulation are free fluid in the Douglas cavus, M-type mucosa and reservoir syndrome (SR). In cases of stenosis SR syndrome is missing, and the mucus is scarce.

Stenosis of the cervical canal as a cause of infertility

In cases of infertility due to stenosis of the cervical canal, there are two methods of treatment: dilation or IUI.

Mechanical dilation by classical Hegar dilatiors under anaesthesia

It extends to Hegar No 8, which ensures that up to 6 months after manipulation, the canal will be open. The best time for this is between day 8 and 10 of the menstrual cycle because then the tissues are softer and more prone to changes. The disadvantage of this method is that the cervical tissue is damaged every time a Hegar dilator is inserted into the canal during classical dilation. This dilation method is used at Dr Shterev Medical Center for Reproductive Health in the period 2012-2015 (Figure 7).

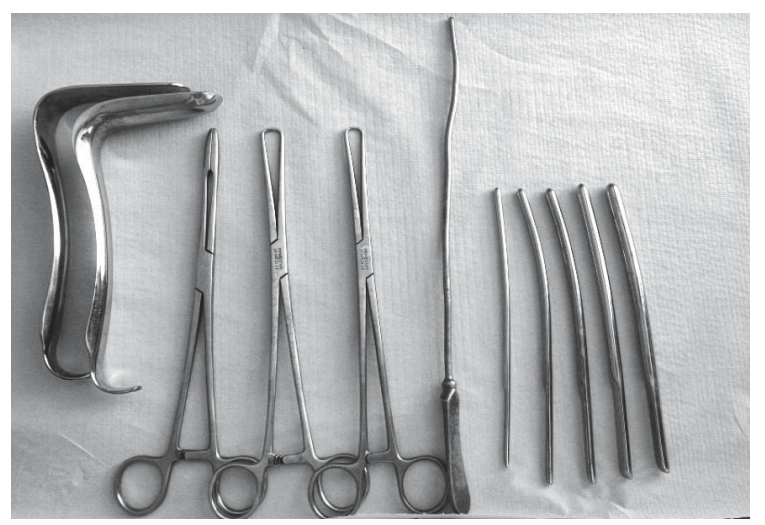

Figure 7. Hegar dilators

Dilation by using the synthetic hygroscopic dilators of the cervical canal

Dilapan is a hydrophilic, synthetic polymer of polyacrylonitrile, shaped as a cervical canal and suited for handling while inserting and taking out of the canal. The advantage of this dilation 
method, compared to the classic one, is that the dilapans are sterile, single-packed for single use. Another advantage is that this dilation does not require anaesthesia and can be done during a routine gynaecological examination. Once placed in the cervical canal, the dilapan absorbs fluid and swells. When it is used to expand the canal to achieve normal fertilisation and pregnancy, it is usually placed in the cervical canal for about an hour. This time is enough to achieve a good result and comparison with conventional metal dilatiors expansion with the dilapan becomes gentler. This new method is used in Dr Kunev Medical centre. It is preferred by patients, easier to use and with better success (Figure 8).

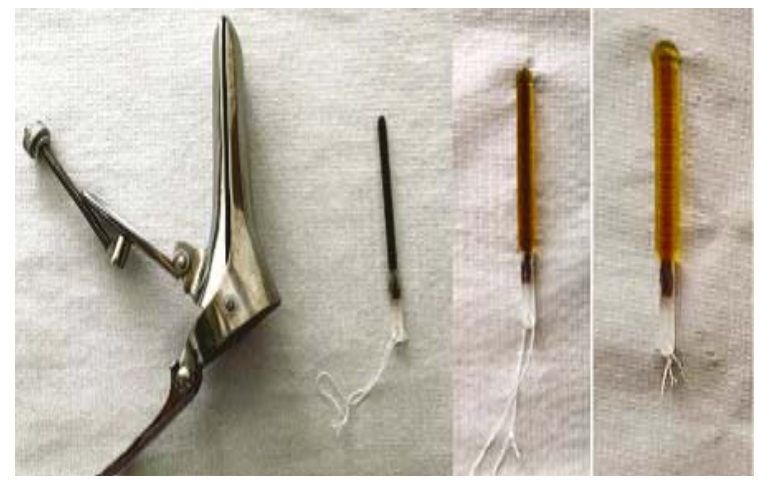

Figure 8. Synthetic hygroscopic dilators (before use; after $60 \mathrm{~min}$; after $120 \mathrm{~min}$ )

\section{IUI}

IUI as part of ART includes the methods of sperm preparation and the introduction of treated sperms into the uterine cavity by a special IUI catheter.

Insemination is a preferred method for treatment of couples in which, in addition to the stenosis of the cervical canal in the woman, deviations from normal sperm counts were observed in the male. Also, this method is more appropriate for older women [6].

\section{Polyps of the cervical canal as a cause of infertility}

Polyps of the cervical canal are relatively common pathology, as $90 \%$ of them are exophytes and are fed through the OECC so that they can be diagnosed in a gynaecological examination with a speculum.

Only $10 \%$ of them are intracervical and are more challenging to diagnose by ultrasound [7].

The cause of sterility is mainly mechanicalocclusive - sperm transport is disturbed, and besides, accumulated leukocytes around the polyp also obstruct normal sperm movement. Polyps delay sperm transport because they often bleed when touching and erythrocytes stop sperm movements.

Treatment methods of cervical canal polyps are surgical. Polyps are removed by polypectomy and abrasion of the cervical canal under anaesthesia. Unfortunately, they often recur, and the woman should be observed for at least 2-3 months after that. After the removal of polyps and healing of the cervical canal, the problem of infertility is usually solved, and the woman becomes pregnant spontaneously, but sometimes IUI is preferred [8].

\section{Results}

The results were based on reproductive consultations and gynaecological examinations for four years at Dr Shterev Medical Center for Reproductive Health. During this period, 252 couples with fertility problems were examined. In 92 of these, a cervical factor was diagnosed as a cause of female infertility, but in many of these cases, it was combined with mild to moderate male factor or hormonal disorders. This means that in $36.5 \%$ of the patients, pathology of the cervix was found that could be the cause of the infertility of the couple.

The presence of cervical factor in a woman is diagnosed by conducting a standard gynaecological examination with a speculum and by ultrasound. The most common pathologies of the cervix that related to infertility were cervical polyps and stenosis of the cervical canal. Cervical polyps were diagnosed in 28 women and stenosis of the cervical canal in 64 women (Table 1).

Table 1. Distribution of patients according to the type of cervical factor

\begin{tabular}{lll}
\hline Type of cervical factor & $\begin{array}{l}\text { Number of } \\
\text { patients }\end{array}$ & $\mathbf{\%}$ \\
\hline Cervical polyps & 28 & 30.5 \\
\hline Stenosis of cervical canal & 64 & 69.5 \\
\hline Overall & 92 & 100.0 \\
\hline
\end{tabular}


Women with cervical polyps were treated by polypectomy and cervical canal abrasion. After removing the polyps and drug therapy, 7 of the patients got pregnant, i.e. the success rate was $25.0 \%$.

Women with stenosis of the cervical canal were treated using two different methods - by dilation or by IUI, depending on the sperm parameters of the male in the couple and the age of the woman. The total number of pregnant women who had stenosis of the cervical canal was 12 . This means that the overall success rate after stenosis treatment of the cervical canal regardless of the chosen method was $18.8 \%$ (Table 2).

Table 2. Success of treatment in relation to the type of cervical factor

\begin{tabular}{llll}
\hline Type of cervical factor & $\begin{array}{l}\text { Number of } \\
\text { patients }\end{array}$ & $\begin{array}{l}\text { Number of pregnant women after } \\
\text { treatment }\end{array}$ & $\begin{array}{l}\text { Success rate } \\
(\%)\end{array}$ \\
\hline Cervical polyps & 28 & 7 & 25.0 \\
\hline Stenosis of cervical canal & 64 & 12 & 18.8 \\
\hline Overall & 92 & 19 & 20.7 \\
\hline
\end{tabular}

Cervical canal stenosis was established in 64 women. This pathology may be a cause of decreased fertility, but it does not always lead to infertility. The methods used were dilation and insemination. Dilation was performed employing two different methods - classical dilation with Hegar dilators under anaesthesia to
Hegar No 8 (in 18 patients), or by a hygroscopic cervical dilator (in 29 of the patients). IUI was performed in 17 patients with cervical canal stenosis. Two patients became pregnant after mechanical dilation, 6 - after placing the dilapan -6 , and $4-$ after insemination. The success rates were $11.1 \%, 20.7 \%, 23.5 \%$, respectively (Table $3)$.

Table 3. Success rate of stenosis treatment depending on the type of treatment method

\begin{tabular}{llll}
\hline $\begin{array}{l}\text { Type of method in the treatment of cervical } \\
\text { canal stenosis }\end{array}$ & $\begin{array}{l}\text { Number of } \\
\text { patients }\end{array}$ & $\begin{array}{l}\text { Number of pregnant } \\
\text { women after treatment }\end{array}$ & $\begin{array}{l}\text { Success rate } \\
(\%)\end{array}$ \\
\hline Dilation by classical Hegar dilators & 18 & 2 & 11.1 \\
\hline Dilation by hygroscopic cervical dilator & 29 & 6 & 20.7 \\
\hline IUI & 17 & 4 & 23.5 \\
\hline Overall & 64 & 12 & 18.8 \\
\hline
\end{tabular}

\section{Discussion}

Causes of infertility in a woman may vary, and the cervical factor is one of the common problems. Methods for its diagnosis are simple and easy to use in routine gynaecological practice. The most common causes of infertility from a cervical origin are cervical polyps and stenosis of the cervical canal. The methods of treatment we propose and the results obtained are consistent with the generally accepted ones and the results of other authors $[9,10]$

Comparing the success rate after treatment of cervical polyps and cervical canal stenosis, we observe $25.0 \%$ vs. $18.8 \%$, respectively. Better success rate and more pregnant women were seen after treatment of polyps than those with stenosis. The difference is noticeable but not statistically significant. This difference is a logical result because polyps are a mechanicalocclusive barrier to sperm transport, and after removal by polypectomy, the problem is usually solved. In contrast, cervical canal stenosis is not always associated with infertility. Our results are similar to those reported by other authors $[7,8]$.

Although stenosis of the cervical canal is not always the cause of infertility, when it is established, it is recommendable to choose a method of treatment. The methods we used in these cases are two - dilation or IUI. Dilation of the cervical canal was recommended to younger women, provided the partner had 
normozoospermia or very slight abnormalities in the spermogram. If a cervical factor in a woman was combined with a male factor, IUI was recommended. As far as dilation methods are concerned, we used classical Hegar dilator and hygroscopic cervical dilator. The success rate was significantly higher when the latter method was used $(11.1 \% ; 20.7 \%)$. Our success rate of IUI in cases of stenosis of the cervical canal is comparable with that after dilation by hygroscopic cervical dilator $-23.5 \%$ and $20.7 \%$, respectively. Other authors have reported similar results $[6,10-12]$.

\section{Conclusions}

Cervical factor in infertility is common but easy to diagnose through routine gynaecological examination and ultrasound. Methods for treating the most common causes of cervical origin (cervical polyps and cervical canal stenosis) are also simple and applicable in routine practice. Besides, most of these methods lead to a higher success rate.

\section{Acknowledgments}

The study is based on the results of the author's clinical experience and is not part of a scientific project. No additional funding.

\section{References}

1. Krzemiński A, Sikorski R, Bokiniec M. Sperm penetration through cervical mucus in infertile couples in relation to selected cervical factors, Hum Reprod. 1988;3(3):353-5.

2. Settlage DS, Motoshima M, Tredway D. Sperm transport from the external cervical os to the fallopian tubes in women: a time and quantitation study. FertilSteril. 1973;24(9):65561.

3. Hafez ES. In vivo and in vitro sperm penetration in cervical mucus. Acta Eur Fertil. 1979;10(2):41-9.

4. Marcus SL The cervical factor in infertility. Journal of Reproductive Medicine. 1969;3(3):138-42.

5. Templeton AA, Penney GC, Lees MM. Relation between the luteinizing hormone peak, the nadir of basal body temperature and the cervical mucus score. Br J Obstet Gynaecol. 1982;89(12):9858 .
6. Tomlinson MJ, Amissah-Arthur JB, Thompson KA, Kasraie JL, Bentick B. Infertility: prognostic indicators for intrauterine insemination (IUI): statistical model for IUI success. Hum Reprod. 1996;11(9):1892-6.

7. Golan A, Ber A, Wolman I, David MP. Cervical polyp: evaluation of current treatment. Gynecol Obstet Invest. 1994;37(1):56-8.

8. Pérez-Medina T, Bajo-Arenas J, Salazar F, Redondo T, Sanfrutos L, Alvarez P, Engels $\mathrm{V}$, et al. Endometrial polyps and their implication in the pregnancy rates of patients undergoing intrauterine insemination: a prospective, randomized study. Hum Reprod. 2005;20(6):1632-5.

9. Makar RS, Toth TL. The evaluation of infertility, pathology patterns. Reviews. 2002;117(1):S95-S103.

10. Scholten I, Moolenaar LM, Gianotten J, van der Veen F, Hompes PG, Mol BW, et al. Long term outcome in subfertility couples with isolated cervical factor. Eur J Obstet Gynecol Reprod Biol. 2013;170(2):429-33.

11. Steures P, van der Steeg JW, Hompes PG, Bossuyt PM, Habbema JD, Eijkemans MJ, et al. Effectiveness of intrauterine insemination in subfertility couples with an isolated cervical factor: a randomized clinical trial. Fertil Steril. 2007;88(6):1692-6.

12. Grund D, Köhler C, Krauel H, Schneider A. A new approach to preserve fertility by using a coated nitinol stent in a patient with recurrent cervical stenosis. Fertil Steril. 2007;87(5):1212. e13-6. 